\title{
A study of Co- morbidities in children aged 6 months to 12 years receiving multiple blood transfusions
}

\author{
Khurram S.A ${ }^{1}$, Prasad C.N ${ }^{2}$ \\ ${ }^{1}$ Dr. Mir Sumsam Ali Khurram, ${ }^{2}$ Dr. C. N. Prasad, Department of Pediatrics, Deccan College of Medical \\ Sciences, Kanchan Bagh, DMRL 'X' Road, Santosh Nagar, Hyderabad, Telangana State, India.
}

Address for Correspondence: Dr. Mir Sumsam Ali Khurram, Associate Professor, Department of Pediatrics Princesses Esra Hospital and Owaisi Hospital, Kanchan Bagh, DMRL 'X' Road, Santosh Nagar, Hyderabad, Telangana State, India. E-mail: dr.sakhurram@gmail.com

\begin{abstract}
Background: Transfusion of blood and blood products is an established way of treating patients who are deficient in one or more blood component. Aim \& objective: Blood transfusion is a vital therapeutic measure which influences the outcome of transfusion dependent subjects. Although survival has increased in these subjects parallel to advances in chemotherapy and chelating, they are more prone to acquiring various co morbidities like transfusion transmitted infection (TTI), transfusion associated adverse event, and iron overload leading to a negative impact on quality and duration of life of the patients. Objective: To assess the consequences of multiple blood transfusions, leading to incidence of co morbidities in recipients. Method: the present study entitled co morbidities in patients receiving multiple transfusions is a descriptive Study and has been carried out in institute during the period of February 2015 to February 2016. Patients receiving multiple blood transfusions were categorized as hemolytic disease and non-hemolytic disease. Patients were screened for transfusion transmitted infection like HIV and HBs Ag, serum ferrites. Result: out of 100 subjects, 86 had hemolytic disease and 14 had non hemolytic disease. The study performed showed that out of 98 total comorbidities, increased serum ferritin contributed to $67.35 \%$, HIV to $10.20 \%$, HbsAg to $15.31 \%$ and $7.14 \%$ was contributed by Transfusion Associated Serious Adverse Events (TASAE). Conclusion: Blood transfusion can lead to severe adverse effects which can cause temporary or permanent morbidity.
\end{abstract}

Keyword: Co-morbidities, Blood transfusion, Blood product

\section{Introduction}

Blood transfusion is a vital therapeutic measure [1] which influences the outcome of transfusion dependent subject. Patients with hematological diseases are major recipients of blood and blood products. Hematological diseases requiring transfusion support over a wide spectrum of Clinical disorders in fetal, neonatal and pediatric age group which included hemoglobinopathies, hemophilia, Immune disorders and bone marrow failure Syndrome in addition to hematological malignancies [2]. Early and regular blood transfusion therapies in these patients decreases the complication of severe anemia and prolong survival In long term, however the beneficial

Manuscript received: $7^{\text {th }}$ May 2017

Reviewed: $17^{\text {th }}$ May 2017

Author Corrected: $26^{\text {th }}$ May 2017

Accepted for Publication: $7^{\text {th }}$ June 2017 effects of transfusion are limited by co-morbidities caused by transfusion transmitted infections, transfusion related adverse events and iron overload [3]. The transmission of infectious disease continues to be the most important complication of blood transfusion [4]. Proper measures if not taken at the time of transfusion land up into great risks including death [5].

The main objective is to determine the consequences of multiple transfusions, the incidence of co- morbidities attached to it and to generate recommendations for blood transfusion services so as to decreases the co- morbidities associated with it thereby increasing the survival rate and prognosis. The aim of the study is to analyze the transfusion reactions and to identify 
associated factors. The present study has benefited the training of health professional, who will be able to work with a degree of safety regarding multiple blood transfusions. Thus the present study will help in decision making.

\section{Material \& Method}

The Present study is a descriptive Study and had been carried out in Pediatric department of Deccan College of Medical Sciences, Hyderabad, Telangana, during the period of Feb-2015 to Feb2016 for which the inclusion criteria were children aged between 6 months to 12 years, either male or female receiving multiple blood transfusion. The study protocol was approved by the ethical committee of the institute.

Definition of multiple transfusion- multiple transfusions are transfusions of whole blood or blood product required to give two or more times over long period of time.

Study Design: Descriptive study.

Study Setting: Tertiary care hospital, high resource setting referral centre.

Study Population: Patients admitted in paediatric wards receiving multiple transfusions.

Study Duration: Duration of study was 1 year.

Sample size: 94

Inclusion Criteria: Subjects of age 6 months to 12 years, either sex male or female, receiving multiple transfusions.

Exclusion Criteria: Subject reporting with Seropositivity (HIV, HBsAg) before receiving multiple blood transfusion, in whom false positive Elisa test was seen. Un willingness to participate in view of concealing their HIV status.

Participants: Patients admitted in the hospital ward of age group 6months to 12 years, male or female undergoing multiple blood transfusions. Patient receiving multiple blood transfusion, were categorized as haemolytic disease and nonhemolytic disease. Diseases included in category of hemolytic anemia were sickle cell anemia and thalassemia. Diseases in non-Hemolytic category were malignancies, aplastic anemia, hemophilia and the patients receiving multiple blood transfusions for acute blood loss, bone marrow failure. HIV: HIV define as a chronic RNA virus infection in the host, when opportunistic or other unusual or persistent infections have occurred or when the CD4 lymphocyte count is less than 200 cells. Virologic assays that directly detect HIV must be used to diagnose HIV infection in children younger than 18 months with prenatal HIV exposure.

$\mathrm{HBsAg}$ is an antigenic determinant found on the surface of the virus. HBsAg can be identified in the serum, 30 to 60 days after variable periods. $\mathrm{HBsAg}$ is the most commonly used test for diagnosing acute $\mathrm{HBV}$ infections or detecting carriers $\mathrm{HBsAg}$ can be detected as 11 or 12 weeks after exposure to HBV, when sensitive assays are used. The presence of HBsAg indicates that a person is infectious, regardless of whether the infection is acute or chronic. Transfusion Associated Serious Adverse Events (TASAE): is an undesirable response or effect in a patient, temporally associated with administration of blood or blood component. Diagnosis: Diagnosis of adverse transfusion reactions based on clinical presentation ad it is common to find an overlapping symptoms in most patients.

Further these cases were assessed for clinical indicators of co-morbidities. Due to multiple blood transfusion evaluation: Patient was screened for transfusion transmitted infection i.e., HIV and HBsAg. Patient's complete blood count indices including pre and post blood transfusion, hemoglobin levels were measures on automated machine. A serum ferritin level was done as an indicator for iron over load in all patients.

HIV: 2 cc blood sample was drown in plain sterile bulb. The sample was screened for HIV $1 \& 2$ by an Enzyme linked immunoassay method whereby the immobilized antigen anti body complex was visualized by means of colour producing reaction HBsAg. Blood was drawn in sterile bottle. Sample was allowed to stand for 10 mints. The test utilizes a combination of monoclonal and polyclonal antibodies to detect elevated level of HBsAg, Complete blood count. Blood was draw in lavender colored, Vacationers containing $5.4 \mathrm{mg}$ K2 EDTA

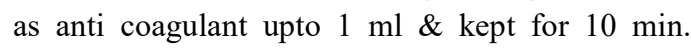
Sample were discarded if dot was present. CBC including pre and post blood transfusion hemoglobin was measured by particle counter. Serum ferritin assay was done for the quantitative determination by latex enhanced immuno- 
turbidimetric method in which an antigen anti body reaction occur between ferritin in a Sample and an anti ferritin anti body occurs.

Statistical Analysis- All detailed clinical laboratory, and observational finding were entered in the pre-designed case data form for statistical analysis. The level of significance was calculated by applying Chi-square test and Fisher's Exact Test for non-parametric analysis: $\mathrm{P}<0.05$ was taken as a significant. All statistical analysis was performed with SPSS predictive. Analytics software: statistics version 18.0 (SPS Inc, Chicago Illinois).

\section{Results}

Out of 100 subjects receiving blood transfusion, 86 had hemolytic disease and 14 had non hemolytic disease. The study showed co-morbidities in 98 subjects out of which serum ferritin contributed to $67.35 \%$, HBsAg to $15.31 \%$, HIV to $10.20 \%$ and Transfusion associated serious adverse events (TASAE) to $7.14 \%$. Transfusion associated serious adverse events: is an undesirable or effect in patient temporally associated with administration of blood or blood component. Classify in two types 1 . When an incorrect or inappropriate blood component has been transfused e g. transfusion of a blood component or product intended for another recipient or a special requirement such as irradiated or CMV negative component was not met. 2: Transfusion of blood component has caused or may potentially cause, an undesirable or unintended outcome for, or to harm to the recipient. Eg. Severe acute transfusion reaction, allergic reaction

Table-1: Co -morbidities in subjects according to frequency of blood transfusions.

\begin{tabular}{|c|c|c|c|c|c|c|c|}
\hline $\begin{array}{c}\text { No. of } \\
\text { Transfusion }\end{array}$ & $\begin{array}{c}\text { Total No. } \\
\text { of Subject }\end{array}$ & $\begin{array}{c}\text { Comorbiditi } \\
\text { es present }\end{array}$ & HIV+ve & HBsAg+ve & $\begin{array}{c}\text { Sr. } \\
\text { Ferritin }\end{array}$ & $\begin{array}{c}\text { Tasae } \\
\text { Comorbidities } \\
\text { Absent }\end{array}$ \\
\hline $2-10$ & 20 & 12 & 5 & 3 & 7 & 0 & 8 \\
\hline $10-20$ & 11 & 7 & 0 & 2 & 5 & 0 & 4 \\
\hline $20-30$ & 8 & 8 & 1 & 0 & 8 & 0 & 0 \\
\hline $30-40$ & 9 & 9 & 0 & 0 & 9 & 3 & 0 \\
\hline $40-50$ & 14 & 12 & 1 & 2 & 11 & 2 & 2 \\
\hline $50-60$ & 17 & 14 & 0 & 2 & 11 & 1 & 3 \\
\hline$>60$ & 21 & 19 & 3 & 6 & 15 & 1 & 2 \\
\hline Total & 100 & 81 & 10 & 15 & 66 & 7 & 19 \\
\hline \multicolumn{7}{|l|}{ P Value for Chi Square Test for Trend is 0.0121 i.e., P<0.05 } \\
\hline
\end{tabular}

Table-1 shows that out of 20 subjects which underwent 2-10 transfusions, $12(60.00 \%)$ experienced comorbidities. Out of 11 subjects who underwent transfusions10-20 times, 7(63.64\%) showed comorbidities. 21 subjects who underwent for more than 60 times, 21 showed co morbidities. The data was analyzed with Chi Square Test for trend and found to be significant $(\mathrm{P}<0.05)$

Table-2: Age wise prevalence of co morbidities in subject.

\begin{tabular}{|c|c|c|c|c|c|c|c|}
\hline Age & $\begin{array}{c}\text { No. of } \\
\text { Subjects }\end{array}$ & $\begin{array}{c}\text { Co morbidity } \\
\text { Present }\end{array}$ & $\begin{array}{c}\text { HIV } \\
\text { Positive }\end{array}$ & $\begin{array}{c}\text { HBsAg } \\
\text { Positive }\end{array}$ & $\begin{array}{c}\text { Sr. } \\
\text { Ferritin }\end{array}$ & $\begin{array}{c}\text { TASAE } \\
\text { Co morbidities } \\
\text { Absent }\end{array}$ \\
\hline <4 Yrs. & 15 & 10 & 1 & 2 & 7 & 0 & 5 \\
\hline 4-8 Yrs & 47 & 30 & 4 & 6 & 32 & 5 & 8 \\
\hline 8-12 Yrs & 38 & 32 & 5 & 7 & 27 & 2 & 6 \\
\hline Total & 100 & 81 & 10 & 15 & 66 & 7 & 19 \\
\hline \multicolumn{7}{|c|}{ P value for Chi Square test for trend was 0.2136 i.e. $P>0.05$} \\
\hline
\end{tabular}

Table-2: Shows in age group <4yrs. 4-8 Yrs. And 8-12 yrs. 10 out of 15 (66.67\%) 39 out of 42 (82.98\%) and 32 out of $38(84.21 \%)$ respectively had prevalence of any one of the comorbidity. The Study shows that Sr. Ferritin levels was higher in 64 . out of 86 subject and 2 out of 14 amongst the hemolytic and non-hemolytic cases. The data was analyzed by fisher's exact test and the difference was found to be highly significant. The study also shows the Sr. Ferritin levels in sickle cell disease were higher in 18 out of 34 subjects and 46 out of 52 amongst the non hemolytic cases. 


\section{Discussion}

Hepatitis is a common comorbidity in patients with multiple blood transfusions according to a study conducted in patients with thalessemia requiring multiple transfusions [6]. Patients who receive multiple transfusions are at high risk of acquiring the comorbidities,including viral hepaptitis thereby having negative impact on their quality and duration of life[7].

Transfusion-dependent patients are more prone to acquiring various transfusion-transmitted infections such as hepatitis B (HBV), hepatitis C (HCV) and human immunodeficiency virus (HIV) [8]. High prevalence of $\mathrm{HBV}$ and $\mathrm{HCV}$ infection were found among Peruvian multi-transfused patients and were associated with a past history and number of blood transfusions, as well as with past hemodialysis procedures [9]. A study was performed during 1999-2000 on multi-transfused patients with haemophilia who are registered by the Shiraz Haemophilia Society. HBsAg, anti-HCV, and antiHIV were checked using a second-generation enzyme-linked immunosorbent assay (ELISA).

Positive tests for anti-HCV and anti-HIV were confirmed by a western blot test. Healthy blood donors were used for the control group. HBsAg, anti-HCV, and anti-HIV were positive in two $(0.71 \%, 95 \% \mathrm{CI}=0.12-2.33), 44(15.65 \%, 95 \% \mathrm{CI}$ $=11.76-20.26)$, and one $(0.36 \%, 95 \% \mathrm{CI}=0.02$ $1.74)$ of the patients, respectively. Positive sera for $\mathrm{HBsAg}$, anti-HCV, and anti-HIV were found in 85 $(1.07 \%), 47(0.59 \%)$, and $27(0.34 \%)$ of the control group, respectively. The rate of anti-HCV was significantly higher in the patients than in the control group ( $\mathrm{p}<<0.0001$ ). The rate of positive anti-HCV was significantly higher than that of positive HBsAg in the patients ( $\mathrm{p}<<0.0001)$. The reverse was correct for the control group ( $\mathrm{p}=$ $0.0008)$. It is concluded that $\mathrm{HCV}$ is the current major problem in multi-transfused haemophiliac patients and more careful pre-transfusion screening of blood for anti-HCV must be introduced in all blood banks [10].

In a study done by Way Seah Lee in 2005 in Malaysia, the risk of Seroconversion of HBV, HCV and HIV in children with multi transfused thalassemia was estimated. The results showed that there were 2605 transfusion episodes and 4154 units of blood transfused. There were 3 new Seroconversions for anti-HCV and none for HBsAg and anti-HIV. The Seroprevalence rates at Starting and endpoints were; HBsAg $(1 \%, 1 \%)$ antiHCV $(10 \%, 13 \%)$ anti-HIV $(0 \%, 0 \%)$ respectively. The magnitude of the problem of transfusion transmitted disease varies country to country depending on disease prevalence. Various measures are taken in a country to make therapy safe for the respective population. There was a risk of 1 to 2 per 1000 recipients, to receive contaminated blood with viral, bacterial or parasitic agent. However there was $50 \%$ of serious morbidity and mortality for the patients if blood transfusion was not undertaken. In India, Hepatitis B/C., HIV, Malaria, Syphilis, Cytomegalovirus, Parvovirus B-19 and bacterial infections were important couses of concern. Hepatitis B and C infection are prevalent in India and carrier rate was about $1-5 \%$ and $1 \%$ respectively .Post transfusion Hepatits $\mathrm{B}$ and $\mathrm{C}$ is a major problem in India, because of low Viremia and mutant strain undetectable by routine ELISA, HIV prevalence among blood donors are different in various parts of the country [11].

Adverse effects of blood transfusion are not unexpected and in many cases are benign. However, some reactions cause serious morbidity and may be fatal. Many of these reactions have an immune basis and may represent inflammatory or allergic responses to infused blood component. Blood transfusions are also associated with a number of chemical and physical complications (eg, citrate toxicity, hyperkalemia, hypothermia). Febrile nonhemolytic transfusion reactions (FNHTRs) are commonly caused by cytokines that accumulate during storage of blood components.

Urticarial (allergic) transfusion reactions occur when soluble substances in the plasma of the blood product react with preexisting $\operatorname{IgE}$ antibodies in the recipient. Anaphylactic transfusion reactions (ATRs) are life-threatening reactions that occur within minutes of a transfusion and are manifested by shock, hypotension and respiratory distress. A well-characterized mechanism for ATRs is the presence of anti-IgA antibodies in patients who are IgA deficient. Transfusion associated circulatory overload is pulmonary edema secondary to 
congestive failure commonly seen in elderly patients, small children, and/or those with compromised cardiac function. Several strategies are available to prevent repeated reactions among patients who are reaction-prone. These include leukocyte reduction to prevent FNHTRs, cell washing to prevent allergic and anaphylactic reactions and some FNHTRs, and various premedication regimens [12].

Patients infected by the human immunodeficiency virus (HIV) as a result of blood transfusions are unique in that their dates of infection are well defined and their medical conditions before infection are known. To characterize the natural history of transfusion-associated HIV infection, we studied 694 recipients of blood from 112 donors in whom AIDS later developed and from 31 donors later found to be positive for HIV antibody. Of the recipients tested, 85 were seronegative, 116 were seropositive, and 19 had AIDS. Of 101 HIVseropositive recipients followed for a median of 55 months after infection, 54 had Centers for Disease Control Class IV disease, including 43 with AIDS.

Life-table analysis suggested that AIDS will develop in 49 percent of infected recipients (95 percent confidence limits, 36 to 62 percent) within seven years after infection. As compared with recipients without AIDS, the 43 recipients with AIDS had received more transfusions at the time of infection (median, 21 vs. 7; $\mathrm{P}=0.01$ ).

HIV-infected blood donors in whom AIDS developed were grouped according to whether AIDS developed within 29 months (the median) after donation (Group 1) or 29 or more months after donation (Group 2).

As compared with the 31 recipients of blood from Group 2 blood donors, the 31 recipients of blood from Group 1 donors were more likely to have AIDS four years after infection (49 percent vs. 4 percent; $\mathrm{P}=0.005$ ) and illnesses resembling acute retroviral syndrome (14 of 24 vs. 5 of $22 ; \mathrm{P}=$ $0.03)$.

We conclude that most recipients of HIV-infected blood become seropositive, that AIDS develops in about half these recipients within seven years, and that the risk may be higher when AIDS develops in the blood donor soon after donation [13].

\section{Conclusion}

Transfusion dependent patients were higher Seroprevalance of HBsAg, focusing the need for stringent screening methods and vaccinating them. Patients receiving multiple transfusion are prove for iron overload indicated by increased serum ferritin levels which requires regular and vigilant monitoring and early chelation therapy to prevent the morbidity in the form of organ damage.

The guidelines for blood transfusion as given FDA need to be strictly implemented, so as to reduce the inappropriate blood transfusion, and thereby reducing the risks for the co morbidities. The blood transfusion Services must aim to ensure easily accessible and adequate supply of safe and quality blood and blood product.

Funding: Nil, Conflict of interest: None initiated, Perission from IRB: Yes

\section{References}

1. Hassall O, Maitland K, Pole L, Mwarumba S, Denje D, Wambua K, Lowe B, Parry C, Mandaliya $\mathrm{K}$, Bates I. Bacterial contamination of pediatric whole blood transfusions in a Kenyan hospital. Transfusion. 2009 Dec;49(12):2594-8. doi: 10.1111 /j.1537-2995.2009.02344.x. Epub 2009 Aug 4.

2. Jain V, Lokesh Mr. Sachdera A. Prevention of Thalessemia. In Hemoglobinopathies. Sachdeva A, Lokeshwar Mr.Shaha N,Agarwal BR, Khama VK, Yadav SP, et al editors. New Delhi : Japee brothers medical publishers (pvt) Ltd: 2006 P.95.

3. Giri, P.A,Deshpande,J.D,Phalke,D.B and Karle,L.B(2012)Seroprevalance of transfusion transmissible infections among voluntary blood donors at a territory care teaching hospital in rural area of India Journal of family medicine and primary care, $1-48-51$.

4. Slonim AD, Joseph JG, Turenne WM, Sharangpani A, Luban NL. Blood transfusions in children: a multi-institutional analysis of practices and complications. Transfusion. 2008 Jan;48(1):7380. Epub 2007 Sep 24.

5. Blundell J.Observation on transfusion of blood by Dr Blundell with a description of his graviator. Lancet 1828,(ii):321-4. 
6. Amar Apuker DN,Kumar A.Vaidya Murti P, Bichile SK,Kairo RH,et al,Frequency of hepatitis $\mathrm{B}, \mathrm{C}$ and $\mathrm{D}$ and human immune deficiency virus infections in multi transfused thalessemia Indian J Gastroenterology 1992;11:80-1.

7. Lukuni ML,Binda P, Mbensa 1, Seroprevalance of HIV infected children with sickle cell anemia. Infant AIDS 1994 Aug 7-12;10:253.

8. Ocak S, Kaya H, Cetin M, Gali E, Ozturk M. Seroprevalence of hepatitis B and hepatitis C in patients with thalassemia and sickle cell anemia in a long-term follow-up. Arch Med Res. 2006 Oct; 37 (7):895-8.

9. Vinelli E, Lorenzana I. Transfusion-transmitted infections inmulti-transfused patients in Honduras. J Clin Virol. 2005 Dec;34 Suppl 2:S53-60.

10. Karimi M, Ghavanini AA. Seroprevalence of hepatitis B, hepatitis $\mathrm{C}$ and human immunodeficiency virus antibodies among multitransfused thalassaemic children in Shiraz, Iran. J Paediatr Child Health. 2001 Dec; 37(6):564-6.

11. Lee WS, The CM, Chan LL. Risk of sereconversion of hepatits $\mathrm{B}$, hepatitis $\mathrm{C}$ and human immune efficiency viruses in children with multi transfused thalessemia major $\mathrm{J}$ paediatric child health 2005;41:265-8.

12. Pomper GJ. Febrile,allergic and nonimmune transfusion reactions.In: Rossi's principles of transfusion medicine. $4^{\text {th }}$ ed.Simon TL, Synder EL, Solheim BG,Stowell CP,Strauss RG, Petrides M, editors.Oxford,UK:Willy-Blackwell Publishing Ltd.; 2009.p.826-46.

13. Ward JW, Bush TJ, Perkins HA, Lieb LE, Allen JR, Goldfinger D, Samson SM, Pepkowitz SH, Fernando LP, Holland PV, et al. The natural history of transfusion-associated infection with human immunodeficiency virus.Factors influencing the rate of progression to disease. $\mathrm{N}$ Engl $\mathrm{J}$ Med. 1989 Oct 5;321(14):947-52.

\section{How to cite this article?}

Khurram S.A, Prasad C.N.A study of Co- morbidities in children aged 6 months to 12 years receiving multiple blood transfusions. J PediatrRes.2017;4(06):376-381.doi:10.17511/ijpr.2017.i06.05. 